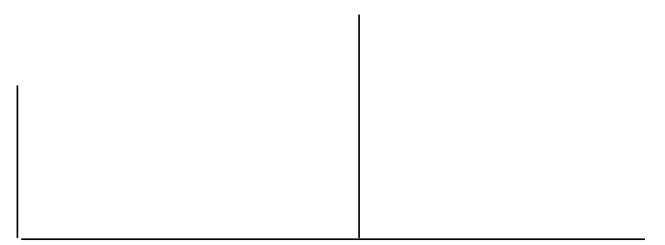

Rev. Latinoam. Psicopat. Fund., VII, 3, 70-81

\title{
Complejidad del dolor y el sufrimiento humano
}

\author{
Carlos Rojas Malpica \\ Joyce Esser Díaz \\ Mariana Rojas Esser
}

\begin{abstract}
En el presente trabajo se discute una cierta concepción unidireccional que, desde el positivismo lógico, se ha venido imponiendo en la investigación médico-psiquiátrica. Aunque la mayoría de los enfermos y de los investigadores insistan en presentar y/o estudiar el dolor y el sufrimiento humano a partir de sus características más molestas y desagradables, estos son fenómenos complejos que no admiten esa sola lectura. Un recorrido por la filosofía, la fenomenología y el psicoanálisis nos aproximará a posibilidades poco exploradas por la medicina, para comprender mejor la complejidad del problema más allá de los síntomas y de la neurofisiología.
\end{abstract}

Palabras claves: Dolor, sufrimiento, placer, antropología médica 
En la investigación médica-psiquiátrica, se ha venido estableciendo un patrón, con arreglo al cual la medida de un fenómeno se toma por el fenómeno mismo. Por ejemplo, es frecuente leer estudios sobre depresión, ansiedad, fobias o esquizofrenia, donde la medida o calibración de la intensidad del trastorno dispensa al investigador de hacerse un amplio juicio clínico sobre el enfermo, o donde incluso da la impresión de que con una escala bien diseñada basta para hacer una investigación de resultados confiables. Buena parte del problema proviene de considerar al "trastorno" como una categoría discreta sin relaciones de tensión y contigüidad con el resto de la vida personal y social del enfermo. No es posible negar los beneficios que desde el positivismo lógico se han aportado a la práctica y la construcción del conocimiento médicos, sin embargo, es el momento de revisar sus limitaciones. Medir la intensidad de un cuadro clínico con cualquiera de los instrumentos de uso frecuente no sustituye el análisis de su complejidad. Ese es un reto que nos plantea una nueva concepción del proceso-salud-enfermedad (PSE) desde la perspectiva de la antropología médica, que se propone rescatar el papel de la subjetividad y del estudio de lo social, en la comprensión de dicho PSE. Veamos una buena aproximación a la complejidad psicofisiológica del fenómeno doloroso. 


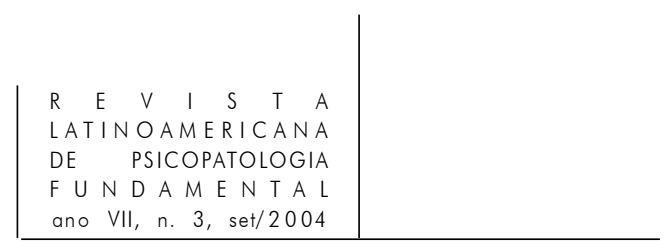

La "International Association for the Study of Pain" (IASP) propone definir el dolor como una experiencia sensorial y emocional displacentera con lesión tisular real o potencial, o mismo, que es descrita en tales términos por el sujeto que lo padece. La IASP reconoce que el dolor es siempre subjetivo y que la incapacidad para comunicar verbalmente esta vivencia, relacionada con los usos tempranos del lenguaje y los símbolos del dolor en las experiencias previas, no niega que el sujeto la esté sufriendo y que requiera de un tratamiento que lo releve de su malestar. Los biólogos reconocen que aquellos estímulos capaces de producir dolor pueden también ocasionar lesiones tisulares, por lo cual la experiencia dolorosa puede asociarse con daño tisular real o potencial, que aunque esté circunscrita a alguna(s) parte(s) corporal(es), es también una experiencia emocional que involucra al sujeto globalmente. Experiencias parecidas al dolor, pero que no son propiamente malestares, como el picor o el prurito, no deberían ser denominadas dolor. Algunas experiencias desagradables (disestesias) pueden ser muy molestas, pero subjetivamente no tienen las cualidades sensoriales del dolor. Muchas personas pueden reportar dolor en ausencia de daño tisular o de alguna alteración fisiopatológica, no habiendo forma de distinguir sus reportes de aquellos relacionados con lesiones tisulares, lo cual se relaciona con problemas psicológicos, por lo que también deben ser reconocidas y admitidas como experiencias dolorosas. Esta definición evita anudar el concepto de dolor con el estímulo, porque la actividad inducida en el nociceptor o en la vía nociceptiva por una determinada noxa no es dolor, el cual es siempre un estado psicológico (IASP, 1994). La definición aportada por la IASP apunta hacia una explicación compleja. Una escala construida a partir de este concepto, debería contemplar diversas dimensiones del problema. Pero se puede avanzar mucho más aún. Por ejemplo, considerar, en el sentido de Max Scheler, el dolor como un sentimiento sensorial o hasta vital, nos aproxima más al sufrimiento y a sus amplias resonancias humanas. Igualmente, el estudio de sus connotaciones culturales y/ o situacionales nos convoca a una ubicación temporal y espacial del sujeto adolorido y, un esfuerzo por repensar los planteamientos del psicoanálisis, nos revelará extraños y poco explorados vínculos entre el placer y el dolor.

\section{La complejidad del problema}

Los psiquiatras de la escuela fenomenológica coinciden en que el dolor, más que una sensación o una percepción, es un sentimiento cualitativamente displacentero, que da lugar a un sufrimiento, de lo cual deriva la profundidad psicológica con que es vivido por el sujeto adolorido. Los sentimientos, de acuerdo 


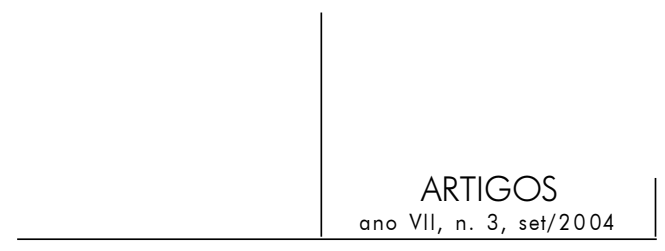

con la estratificación propuesta por Max Scheler pueden ser clasificados en sensoriales, como en el dolor somático, localizable y preciso; vitales, como en el dolor moral de la melancolía; psíquicos, como el sentimiento que acompaña al miedo; y espirituales, cuya mejor representación la encontramos en la culpa (Alonso-Fernández, 1989). La palabra dolor esta cargada de una rica polisemia que desborda lo estrictamente sensorial. Rebuscando en su etimología, LópezIbor Aliño, nos propone lo siguiente:

Si comparamos las palabras en diversas lenguas esto parece muy claro, y más buscando su etimología. El dolor es daño (mal, dicen los franceses), es pena (pain, dicen los ingleses), es sufrimiento y enfermedad (doencia en portugués, dolencia). Pena es una palabra de origen griego (poiné), que significaba castigo o multa; en latín "poena", de donde derivan "penalis" como "paenitentia". Así el dolor es culpa o castigo. El dolor, como la enfermedad en el antiguo testamento, es penitencia por una culpa pasada, personal o de sus antecesores. (1972, p. 48)

Ahora bien, al dolor, el sufrimiento y la angustia se le otorgan virtudes reveladoras de la condición humana, motivo por el cual han dado lugar a tantas reflexiones de trascendencia filosófica. Durante la Edad Media y el Renacimiento, los místicos cristianos dieron una bienvenida al dolor y al sufrimiento como una vía de purificación y expiación que aproximaba al cielo. Se aborrecía la vida terrenal y se trataba de emular la pasión de Cristo para hacerse grato a los ojos de Dios en el momento postrero. Las coplas de Santa Teresa (...venga ya la dulce muerte, el morir venga ligero...) y de San Juan de la Cruz (... que muero porque no muero...) son expresión sublimada de tal estado de tensión espiritual. El látigo y el silicio eran compañeros obligados en las celdas de los monasterios medievales para las atormentadoras acedías de los monjes. En los ejercicios espirituales de Ignacio de Loyola se recomendaba imaginarse envuelto entre miasmas y azufres para aprender a aborrecer al demonio. Miguel Ángel divinizó el dolor de la Madre, de sufrido rostro, reclinado sobre el cuerpo del hijo yaciente en su regazo, en el Conjunto Escultórico de "La Piedad", que se expone en la Capella della Pietá de la Basílica de San Pedro. Se trataría en estos casos, de un sufrimiento bendecido o de un dolor glorificado desde una perspectiva sensible y valorativa, que debe oponerse al dolor maldecido, que envilece la existencia y "prohibe la ilusión" (Orcajo, 1995, p. 236). Esto amplia la significación ontológica del fenómeno doloroso. Remontado ya el renacimiento, Sören Kierkegaard se ocupó de la función reveladora de la angustia y de la fe: "fuera de la fe no hay mas que desesperación, la de no querer ser uno mismo o la de querer serlo" (apud Chiodi, 1962, p. 6). Los filósofos existencialistas han encontrado en la angustia una emoción que nos confronta con la nada o con la libertad. Angustia es palabra vinculada con angosto, con la estrechez física y vital que nos imponen 


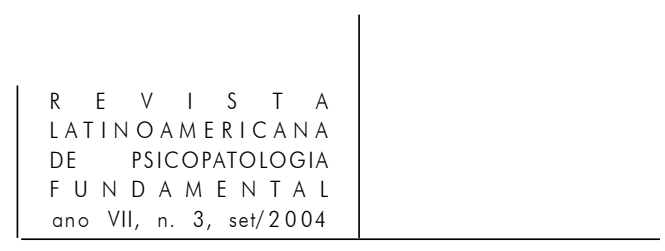

los límites personales y filogenéticos. Un primer encierro angustioso se percibe en las posibilidades de nuestra fuerza física, que resulta inmediatamente trascendido desde la más remota antigüedad a través de la palanca; otro, más elaborado, nos lo imponen los límites sensoriales que son rebasados gracias al telescopio; seguidamente viene el cerco de la comunicación determinado por la lengua filogenética que resulta transpuesto por la música y, por último, el límite de nuestras capacidades mentales, expandido por el mundo de los enseres y la cibernética. Queda pendiente una asignatura que es el límite de la vida, trabajada incesantemente por la medicina y la biotecnología (García Bacca, 1984; Rojas Malpica, 2002). A una función sana y deseable de la angustia se asoma la angustia francamente patológica que corroe al sujeto de temor a la muerte y desborda las posibilidades del Yo para hacerle frente. Pero el dolor y el sufrimiento pueden también ser considerados fuentes de maduración, crecimiento y virtudes enaltecedoras, tanto en la vida cotidiana como en situaciones heroicas. Víctor Frankl (1957) afirmaba que es "el análisis de la existencia el que nos descubre el sentido real del sufrimiento, el que nos revela que el dolor y la pena forman parte, con pleno sentido, de la vida, del mismo modo que la indigencia, el destino y la muerte. No es posible separarles de la vida sin destruir su sentido mismo" (p. 138) Así que de momento, reconozcamos que a la complejidad psicofisiológica asumida en la definición de la IASP debe agregarse la dimensión sentimental, filosófica, religiosa y cultural del problema.

Un antecedente remoto del vínculo entre placer y dolor lo encontramos en el relato que hace Platón en "Fedón o del Alma", a propósito de la visita que algunos amigos hacen a Sócrates momentos antes de cumplirse la sentencia fatídica. Sócrates, a quien su carcelero acaba de retirar los herrajes, se soba los tobillos con fruición y le dice a sus visitantes:

Es cosa singular, amigos míos, lo que los hombres llaman placer y ique relaciones maravillosas mantiene con el dolor, que se considera su contrario!. Porque el placer y el dolor no se encuentran nunca a un mismo tiempo, y sin embargo, cuando se experimenta el uno, es preciso aceptar el otro, como si un lazo natural los hiciera inseparables. Siento que a Esopo no haya ocurrido esta idea, porque hubiera inventado una fábula, y nos hubiese dicho que Dios quiso un día reconciliar estos dos enemigos, y que no habiendo podido conseguirlo los ató a una misma cadena, y por esta razón, en el momento que uno llega, se ve bien pronto llegar su compañero. Yo acabo de hacer la experiencia por mi mismo, puesto que veo que al dolor que los hierros me hacían sufrir en esta pierna, sucede ahora el placer. (Platón, s/f)

No sabía Sócrates, que al sobarse sus tobillos provocaba la inhibición de algunas fibras de conducción del dolor, favoreciendo el predominio de otras neuronas segmentarias que en la médula liberan sustancias opioides, con todo lo 


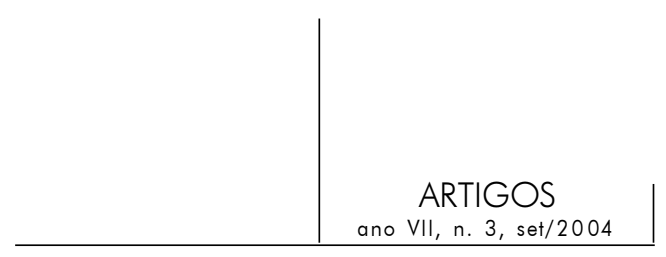

cual se activa un mecanismo regulador del haz espinotalámico que lleva la información dolorosa hasta el SNC. No lo sabía, pero lo intuía y expresaba en los términos complejos de su reflexión. Y es que la relación con la muerte, el sufrimiento y el dolor, dividió luego a los filósofos griegos entre estoicos y epicureistas. Los estoicos cultivaban la serenidad como estilo de vida y para ellos la felicidad consistía en liberarse de las pasiones (apatía), mientras que los epicureistas trataban de vivir en el placer a toda costa y defendían el derecho a llevar una vida apasionada. Ese vínculo entre el dolor y el placer es retomado siglos después por Sigmund Freud, especialmente en su ensayo titulado "Mas allá del principio del placer", escrito en 1920 (Freud, 1948).

\section{Dolor, placer, realidad, lenguaje y cuerpo}

Para Freud, el aparato psíquico se gobierna por una tensión permanente entre el principio del placer y el principio de la realidad. Tanto el placer como el displacer se ligan al Yo en calidad de sensaciones conscientes, pues las percepciones son al Yo lo que los instintos al Ello, donde reside la pulsión erótica junto a la pulsión tanática. Cuando ambas pulsiones son percibidas en la esfera consciente adquieren la condición de vivencias. El Yo debe administrar las demandas del Ello, gobernadas por el principio del placer, ajustándolas al principio de la realidad, que tiene por función primordial conservar la vida y protegerla de las amenazas exteriores de acuerdo con un instinto de conservación alojado en el mismo Yo. La acumulación de energía produce una tensión resentida en el Yo como malestar, mientras que la liberación del malestar se vive como una experiencia placentera. El aparato anímico debe mantener baja la cantidad de excitación, favoreciendo su drenaje por diversas vías, pero también seleccionando los estímulos externos para impedir un ingreso masivo insoportable y doloroso. De alguna manera el Yo, considerado por Freud como la superficie del aparato psíquico, la membrana celular, y la corteza cerebral, cumplen funciones similares en la relación del individuo con el mundo exterior, permitiendo la entrada de sólo aquellos estímulos necesarios para mantener el equilibrio interior y un adecuado contacto con la realidad. La vulneración de la barrera sensorial puede producir dolor, y el derrumbe del Yo, mucho temor y sensación de perder el control. Las fuentes de displacer pueden conformarse de placeres que no fueron vividos como tales en el momento del desarrollo psicoevolutivo, como la mayoría de los displaceres neuróticos, o por percepciones penosas procedentes del exterior, bien porque son por sí mismas nocivas o porque movilizan expectativas displacenteras asociadas con riesgo de daño. Pero Freud, después de un largo recorrido reflexivo 


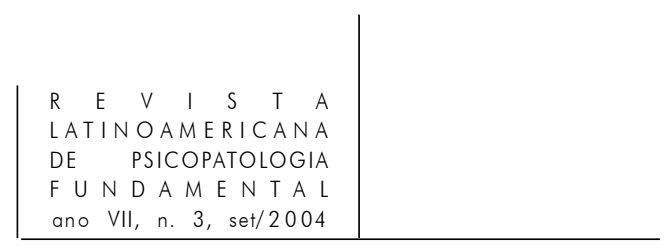

por la clínica y la biología, encontró que en la vida anímica hay una obsesión de repetición que se ubica más allá del principio del placer y que depende de una fuente energética distinta, mucho más elemental, instintiva y primitiva. Se refería a los juegos repetitivos de los niños, pero también a aquellas conductas reiterativas de algunos adultos que terminan siempre en aparatosos fracasos y episodios dolorosos, que no parecen reportar placer alguno a sus actores. ${ }^{1}$ De alguna manera recuerdan el mito de Sísifo, y su análisis, demasiado complejo para resumirlo en estas breves líneas, lo condujo a postular una pulsión de muerte o todestriebe que se mantiene anudado pero en conflicto permanente con la pulsión sexual o instinto de la vida:

Esto es favorable a la hipótesis de que el proceso de la vida del individuo conduce, obedeciendo a causas internas, a la nivelación de tensiones químicas, esto es, a la muerte, mientras que la unión con una sustancia animada, individualmente diferente, eleva dichas tensiones y aporta, por decirlo así, nuevas diferencias vitales, que tienen luego que ser agotadas viviéndolas. (Freud, 1948 , p. 1.135 , v. I)

La liberación de la energía pulsional erótica debería ser siempre grata, mientras que la liberación tanática debería acompañarse de vivencias destructivas de agresividad y odio dirigidos contra el propio sujeto o contra el exterior. Sin embargo, nada es tan simple en la vida psíquica. En su emergencia, las pulsiones deben sortear las deformaciones que les impone el aparato anímico y el principio de la realidad. De esta manera lo expresaba Schopenhauer mucho antes que Freud:

Así como un arroyo corre sin remolinos mientras no encuentra obstáculo alguno, de igual modo en la naturaleza humana, como en la naturaleza animal, la vida se desliza inconsciente y distraída cuando nada se opone a la voluntad. Si la atención está despierta, es que se han puesto trabas a la voluntad y se ha producido algún choque. Todo lo que se alza frente a nuestra voluntad, todo lo que se atraviesa o se le resiste, todo lo que hay desagradable o doloroso, lo sentimos enseguida con suma claridad. (Schopenhauer, 1993, p. 117-8)

En términos de la escuela lacaniana lo real es aquello que se manifiesta por su resistencia al dominio. Lo real produce sufrimiento pero también induce fulguraciones de la inteligencia que emancipan al sujeto de una relación sometida con la cotidianidad, todo lo cual es especialmente visible en el mundo del trabajo. Cioran exploró hasta los límites cuando propuso esta ironía: "de todo lo que nos

1. En psicopatología se habla de conductas anancásticas. Laín Entralgo (1970, p. 53) refiere: "Pero cuando los nomoi convencionales o sociales dejan de actuar, algo hay en la Phýsis por lo cual esta retorna a su condición originaria, a su más propio y radical nómos, a su anánké, a su propia y radical necesidad interna". 


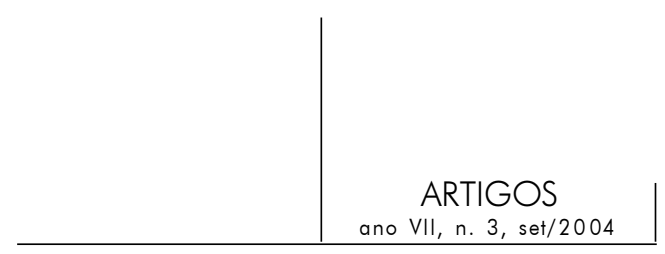

hace sufrir, nada tanto como la decepción nos produce la sensación de que alcanzamos por fin lo verdadero" (Cioran, 1995, p. 98).

En la pareja sado-masoquista dolor y placer (eros y tanatos), se anudan y yuxtaponen en una relación difícil de deshilvanar. Freud propuso que en el masoquismo el castigo expiaba la culpa por deseos agresivos e incestuosos, y que la primera experiencia la vivía el(la) niño(a) al recibir un castigo en las nalgas, que al mismo tiempo era excitante y doloroso. Habría que analizar más detenidamente la culpa en la pareja sado-masoquista para acreditar ese argumento, porque de lo que se trata es de una erotización desmedida del componente agresivo presente en toda relación madura, que en este caso llega a hacerse indispensable para lograr la excitación y el clímax. Lo que resulta evidente es que el(la) masoquista ya va muy excitado(a) con sus fantasías a la relación, y que trata de postergar al máximo la ocurrencia del clímax, hasta haber sido suficientemente humillado y envilecido por la pareja. Con lo cual queda en evidencia que el dolor es sólo una vía para aproximarse a la satisfacción final, pero que a la larga puede hacerse autónomo hasta constituirse en un masoquismo erógeno. Quizás algunas veces pueda hablarse también de un masoquismo primario, en cuyo caso habría que aceptarlo "como una oportunidad que se le presenta a la subterránea pulsión tanática para su gratificación vicariante" (Vives Rocabert, 1997, p. 4). En todo caso, en el masoquismo hay simultáneamente un incremento de la tensión sexual y dolorosa, lo cual puede potenciar la vivencia liberadora de la experiencia orgásmica. En las orgías satánicas de algunos grupos de adictos, se celebran misas negras en medio de un frenesí colectivo con drogas, música ácida, sacrificios rituales y sexo perverso. La sexualidad parece ser arrastrada por una ofuscación encefálica difusa. La impresión que se obtiene en la clínica es que la transgresión de ciertos umbrales deja al cerebro inservible para la estimulación fina y sutil. De allí en adelante sólo tiene sentido la experiencia frenética y la estimulación brutal. De allí que algunos(as) de estos(as) enfermos(as) se autolesionen para lograr avivar su sensibilidad embotada. La medicina forense reconoce que algunas personas piden ser estranguladas en el momento del orgasmo, con lo que parece lograrse una dilatación temporal de la vivencia, y algunas veces, también la muerte.

Se ha reportado que algunos niños nacen sin nociceptores, lo cual condiciona una incapacidad para percibir el dolor (Painless Disease). No son conductas deliberadas, pero se lesionan o se queman y llegan hasta mutilarse sin sufrimiento ninguno. Parecen carecer de instinto de conservación y viven muy pocos años. Al otro extremo, hay personas con un bajísimo umbral de sensibilidad dolorosa, bien por una disposición genética o porque una enfermedad crónica ha facilitado la proliferación de nuevos contactos neuronales transmisores de dolor, o mismo, que las vías periféricas del dolor han comenzado a activarse 


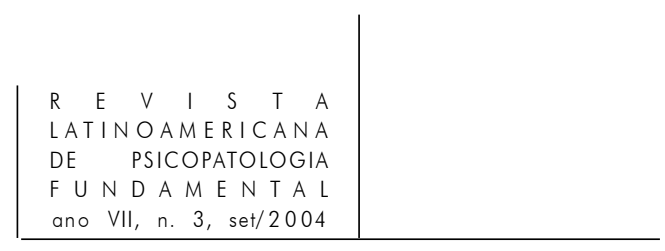

autónomamente o con estímulos sub-umbrales a la manera de un kindling, como una especie de epilepsia periférica, lo que daría lugar a una enfermedad hiperalgésica (Painfull Disease). Ambas situaciones podrían hacer pensar que la sensibilidad dolorosa se distribuye a la manera de una campana de Gauss. Sin embargo, se trata sólo de una cuestión de umbrales, pues la sensibilidad también resulta influenciada por factores como la hora del día, los ritmos biológicos, el estado afectivo, las circunstancias personales y los valores, de tal manera, que la reflexión nos devuelve a la complejidad del problema. Algunas personas llegan a activar fenómenos dolorosos con estímulos que normalmente no los producen, como en el caso de la alodinia, donde un leve roce o un ruido molesto pueden generar una respuesta dolorosa, todo lo cual representa una diferencia cualitativa con respecto a la hiper-algesia. Esta última situación nada tiene que ver con los fenómenos inflamatorios que pueden producirse en la piel bajo la sugestión hipnótica de estar siendo quemado por un cigarrillo, como tampoco la hay entre Painless Disease y aquellas personas que en estado de trance místico danzan sobre brasas sin lastimarse. En situaciones de estrés severo se puede producir un aumento brusco del umbral doloroso y se le conoce como Analgesia Inducida por Estrés, la cual está condicionada por una liberación de opioides endógenos (Flor y col., 1994). Ello explica porqué las heridas en combate pueden pasar desapercibidas, pero también la adicción comportamental de los buscadores de sensaciones y deportistas de alto riesgo, así como el enorme goce en situaciones límites, donde puede haber dolor, temor y peligro real de perder la vida. La impresión que se recoge en la clínica, es que en dichas situaciones el cuerpo se transforma en un radar de sensaciones que obnubila el instinto de conservación y el principio de la realidad, generándose un goce ubicado "mas allá del principio del placer" (Rojas Malpica, 2000).

La necesidad de ser escuchado y atendido por el otro se hace presente desde el momento mismo del nacimiento. La primera palabra es un grito. A partir de allí podría elaborarse una semiología de la queja que diga mucho acerca del dolor y el sufrimiento humano. La primera conclusión sería que hablar cura y que la represión del acto simbólico incrementa la tensión dolorosa. Habrá entonces que considerar la función simbólica, en el estudio de la complejidad del problema, asignándole un papel determinante en la estructuración y representación de la experiencia (Benaím Pinto, 1983). Hoy se sabe que en la evocación de las situaciones de estrés agudo se produce un bloqueo funcional de las áreas cerebrales del leguaje, lo cual parece ocurrir también en las pesadillas, haciendo mucho más difícil integrar esas experiencias en la esfera consciente (Kluck, 2002).El que escucha la queja, difícilmente podrá quedar indiferente, de allí que se le considere un fundamento de la empatía y el acto médico. 


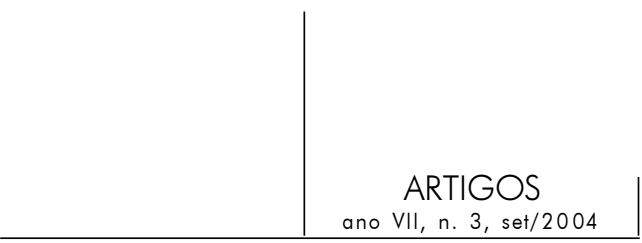

El problema de la percepción del dolor y el sufrimiento por el observador obliga a detenerse en el análisis de la empatía. Cuando nos relacionamos empáticamente con el otro reproducimos en nuestra intimidad lo que el otro siente y expresa, a la manera de una intuición participante (Celis de Oliveros, 1990). Algunos criminales, incapacitados para ponerse en la piel de sus víctimas, lamentablemente no perciben el dolor expresado en sus gestos, porque serviría como señal eficaz para detener la agresión. Sin embargo, la tendencia empática parece estar inscrita en nuestra constitución humana y de alguna manera, permite también aproximarnos afectivamente a los animales, especialmente aquellos mamíferos que tienen cierta expresividad gestual. De allí la solidaridad militante con los animales, expresada por algunos grupos ecologistas, cuya mirada empática propone "una relación visceral" con el ambiente que llegue hasta el universo inanimado, a través de un inmenso bucle de eco-comunicación que comprenda las relaciones intra e inter-específicas en los tres reinos de la naturaleza. Así fundamentan los teóricos del "desarrollo sustentable" la necesidad de percibir el sufrimiento planetario (Martínez Pérez, 2002).

\section{Conclusión}

Sobre un tema tan complejo sólo cabe una conclusión aproximada y provisional. A lo mejor, una metáfora estética resulta superior a una descripción de la ciencia positiva, atrapada en conceptos taxativos y redondos. Un cuadro del Veronés (Paolo Callari, 1528-1588) que se exhibe en The Metropolitan Museum of Art (1994) de Nueva York, presenta a "Marte y Venus unidos por el Amor”. Se observa al Dios de la Guerra y la Diosa del Amor que miran con simpatía a un angelito que se entretiene con el lazo que la Diosa lleva en el tobillo, mientras que en el fondo, Cupido detiene a un caballo colocando delicadamente una espada ante sus piernas. Se trata de un hermoso retrato que ha sido trabajado cuidando muy bien la armonía. No se percibe ningún exceso en su elaboración. Sin embargo, nos recuerda muy bien la tensión existente entre el dolor y la vida en las pasiones humanas, así como los diversos y complejos revestimientos que eligen para su expresión, que recorren desde "El Grito" desgarrado de Munch y el doloroso gesto de la Virgen María en "La Piedad” de Miguel Ángel, hasta la delicada estética del Veronés. Ya para finalizar, podemos afirmar que la compleja problemática del dolor y el sufrimiento, no puede ser respondida con lo que ya se sabe. Es necesario entonces cometer la imprudencia de acercarse a los bordes mismos del conocimiento, para iluminar el abismo de todo aquello que ignoramos y, desde allí, exigir una nueva forma de saber.

\section{9




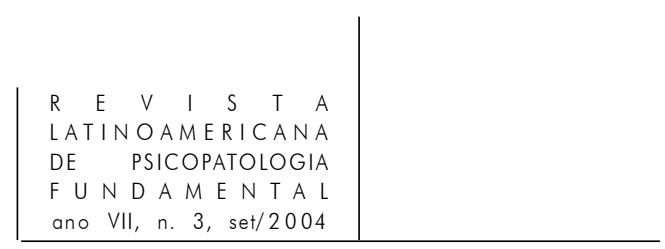

\section{Referencias}

Alonso-Fernández, Francisco. Psicología médica y social. Barcelona: Salvat, 1989.

Benaim Pinto, Henrique. Significación de la queja. Ediciones del Rectorado. Caracas: Universidad Central de Venezuela, 1983.

Celis de Oliveros, Eileen. Empatía y medicina. Su determinación en estudiantes de medicina. Ediciones del Rectorado. Valencia, Venezuela: Universidad de Carabobo, 1990.

Cioran, E.M. Ese maldito Yo. Barcelona: Tusquets, 1995.

ChIodi, Pietro. El pensamiento existencialista. México: UTEHA, 1962.

Flor, H. y Birbaumer, N. Basis issues in psychobiology of pain. In: Gebhart, G.F., Hammen, D.L. \& Jenssen, T.S. (eds.). Proceedings of the $7^{\text {th }}$ World Congress on Pain. Progress in Pain Research and Magnagement. Seattle: IASP Press,1994. p. 113-25. v. II.

Freud, Sigmund. Obras Completas. Madrid: Biblioteca Nueva, 1948. v. I y II.

García BACCA, J.D. Transfinitud e inmortalidad. Caracas: Editora Josefina Bigott, 1984. International Association for the Study of Pain. In: Merskey, H. \& Bogduk, N. (eds.). Classification of Chronic Pain. IASP Task Force in Taxonomy. Seattle: IASP Press, 1994. p. 209-14.

80 KLuCK, John. Trastorno de estrés postraumático. In: JACOBSON, J.L. y JACOBSON, A.M. (eds). Secretos de la psiquiatría. México: Mc Graw Hill Interamericana, 2002. p. 106-12. t. I.

Laín Entralgo, Pedro. La medicina hipocrática. Madrid: Revista de Occidente, 1970. LóPez-Iвor Aliño, J.J. Los equivalentes depresivos. Madrid: Paz Montalvo, 1972.

Martínez Pérez, Naudys. La herencia ambiental del hombre. Barquisimeto, Venezuela: Consejo de Desarrollo Científico, Humanístico y Tecnológico de la Universidad Centro Occidental "Lisandro Alvarado", 2002.

OrCajo, Angel. El sufrimiento. In: Rojas Malpica, C. (Director-Curador). Filosofía en la medicina II. Ediciones del Rectorad. Valencia,Venezuela: Universidad de Carabobo, 1995, p. 233-48.

Platón. Diálogos. Buenos Aires: Editorial Panamericana (s/f).

Rojas MalpicA, Carlos. Adicción al trabajo. Psicopatología, v. 20, n. 1, p.15-26, EneroMarzo/2000.

El enfermo mental ante la muerte. Consejo de Desarrollo Científico de la Universidad de Carabobo. Valencia, Venezuela, 2002.

SCHPENHAUER, Arthur. El amor, las mujeres y la muerte. Madrid: Editorial EDAF, 1993.

The Metropolitan Museum of Art. Guía. New York, NY, 1994.

VIVEs Rocabert, J. La perversión masoquista. XXXVI Congreso Nacional de Psicoanálisis de la Asociación Mexicana. Mérida, Yucatán, México, 1997. 


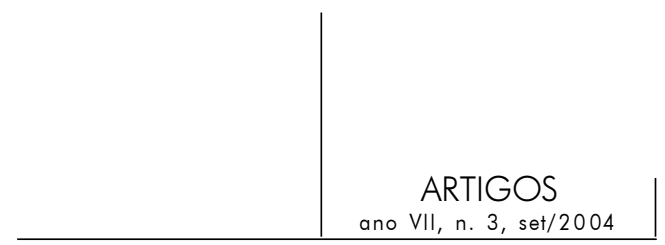

Resumos

No presente trabalho discute-se uma certa concepção unidirecional que, desde o positivismo lógico, se tem imposto na investigação médico-psiquiátrica. Embora a maioria dos doentes e os pesquisadores insistam em apresentar elou estudar as dores $e$ o sofrimento humano a partir das suas características mais incomodas $e$ desagradáveis, esses são fenômenos complexos que não admitem essa única leitura. Um percorrido pela filosofia, a fenomenologia e a psicanálise nos aproximará a possibilidades pouco exploradas pela medicina, para compreender melhor a complexidade do problema além dos sintomas e da neurofisiologia.

Palavras-chave: Dor, sofrimento, prazer, antropologia médica

Dans ce travail on discute une certaine conception unidirectionelle qui du point de vue du positivisme logique s'est progressivement imposée dans la recherché medicopsychiatrique. Bien que la majorité des maladies et des chercheurs insistent en présenter et/ou étudier la doleur et la souffrance humaine à partir de leurs caractéristiques plus dérangeantes et désagreables, ceux-ci sont des phénomenès complexes étant susceptibles d'autres lectures. Un parcours à travers de la philosophie, la phénoménologie et la psychanalyse, nous a permis de proposer des posibilites très peu explorées par la médecine, pour mieux comprendre la complexité du problème au delá des symptômes et de la neurophysiologie

Mots clés: Douleur, douffrance, plaisir, antropologie médicale

This article discusses a unidirectional conception that, ever since logical positivism, has prevailed in medical psychiatric investigation. Though most patients and researchers insist on presenting and/or studying human pain and suffering through their most disturbing and unbearable characteristics, they are complex phenomenon that are not easily reduced to such a limited analysis. A journey through philosophy, phenomenology and psychoanalysis will allow us to propose probabilities, seldom explored by the medical sciences, with a view to understanding the complexity beyond symptoms and neurophysiology.

Key words: Pain, suffering, pleasure, medical anthropology

Versão inicial recebida em setembro de 2003

Aprovado para publicação em fevereiro de 2004 